\title{
Methodology to improve the accuracy of the model in photovoltaic systems
}

\author{
Jose Galarza \\ Department of Electrical and Electronic Engineering, National University of the Center of Peru, Peru
}

\begin{tabular}{|c|c|}
\hline Article Info & ABSTRACT \\
\hline Article history: & \multirow{10}{*}{$\begin{array}{l}\text { The present research proposes a methodology to improve the estimation of the un- } \\
\text { known parameters of the unitary diode model of the photovoltaic panel. To check the } \\
\text { accuracy, a comparison with other methodologies known in the scientific literature is } \\
\text { made. Through an iterative process, the best value of the series resistance and the } \\
\text { ideality factor for different temperature and irradiance conditions are identified. The } \\
\text { objective is to determine a simplified model that accurately estimates the power sup- } \\
\text { plied by a photovoltaic installation. To check the effectiveness of the methodology, } \\
\text { a comparison was made between the power estimated by the model and the power } \\
\text { measurements of an experimental photovoltaic installation. The results based on sta- } \\
\text { tistical indicators show that the proposed methodology determines a simplified model } \\
\text { of the unitary diode with a better capacity and accuracy with respect to the known } \\
\text { methodologies. }\end{array}$} \\
\hline Received Oct 9, 2020 & \\
\hline Revised Dec 26, 2020 & \\
\hline Accepted Jan 15, 2021 & \\
\hline Keywords: & \\
\hline & \\
\hline Cell temperature & \\
\hline erimental measurements & \\
\hline radiance & \\
\hline & \\
\hline
\end{tabular}

Photovoltaic system

Statistical indicators

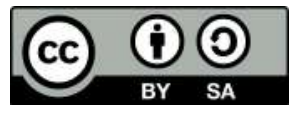

\section{Corresponding Author:}

Jose Galarza

Department of Electrical and Electronic Engineering

National University of the Center of Peru

3909 Mariscal Castilla Avenue, Huancayo, Peru

Email: jgalarza@uncp.edu.pe

\section{INTRODUCTION}

Statistical information on renewable energies shows that these technologies are growing worldwide, with the highest participation rates in Europe and Asia [1]. In 2050, electricity generation with solar and wind systems will have a $79 \%$ share of the electricity generation matrix in the United States, and electricity generation for self-consumption through photovoltaic (PV) panels will increase fivefold [2]. The scientific literature presents different models of the PV system; the single diode model (SDM) is accepted for its simplicity and accuracy [3-12]. In the SDM, the I-V characteristic of the PV system is represented by a non-linear equation coupled with five parameters: photoelectric current $\left(I_{L}\right)$, inverse diode saturation current $\left(I_{o}\right)$, ideal diode factor $\left(n_{i}\right)$, series resistance $\left(R_{s}\right)$, and parallel resistance $\left(R_{s h}\right)$ [6]. The five-parameter SDM can be simplified to four parameters by neglecting the $R_{s h}$ value $[13,14]$. The technical data of the PV provided by the manufacturer are used to determine the five parameters of the SDM under standard test conditions (STC). In [15, 16] $R_{s}, R_{s h}$ and $n_{i}$ are considered constant, calculated with empirical and thermal formulations; in [17] the factor $n_{i}$ is chosen according to the PV technology; in $[13,14,18,19]$, experimental data was used for the estimation of $n_{i}$ through thermal equations and coefficients that allowed the adjustment of I-V curves. Temperature and irradiance variables directly affect the five parameters of the SDM. Through the superposition principle, the parameters calculated in STC are corrected for different temperature and irradiance conditions [4-8]. The calculation of the parameters of the SDM has been widely evaluated with commercial PV modules. Several 
authors establish different criteria for the calculation of the parameters. The results estimated by each methodology are different for the evaluation of the same photovoltaic panel, in some cases very divergent [5-7, 17, 20]. In this research, the SDM is analyzed using experimental measurements to determine a simple and accurate model, considering only four parameters $\left(R_{s}, n_{i}, I_{L}\right.$, and $\left.I_{o}\right)$. The contributions of this work are the following:

- Determination of $I_{L}$ and $I_{o}$ through an analytical method; in an iterative way $R_{s}$ was determined through a progressive increase of $n_{i}$.

- Study of the variation and influence of $R_{s}$ and $n_{i}$ in the accuracy of SDM.

- Determination of the simplified SDM to accurately estimate the power supplied by the PV system to the electric grid.

- The proposed methodology is analyzed using experimental measurements of a $3 \mathrm{kWp}$ installation. The results show that the variation of $n_{i}$ during the day follows the behavior of the irradiance. The estimation of this coefficient is determined to obtain the accuracy in the SDM.

This paper is organized as follows. Section 2 addresses the single diode model and the proposed methodology. Section 3 reports the simulations results and statistical indicators for PV power assessment. Finally the conclusion is given in section 4 .

\section{MATERIALS AND METHODS}

\subsection{Experimental PV system}

The experimental PV system used in this research is part of the pilot project executed by the Ministry of Energy of Peru. The installation is located in the city of Huancayo,Peru, as part of the Renewable Energy Laboratory of the Faculty of Electrical Engineering of the National University of the Center of Peru. The PV system is shown in Figure 1. The project has 10 poly-crystalline silicone panels MAXPOWER CS6U325 [21] from the manufacturer CanadianSolar. The technical characteristics are shown in Table 1. These panels have been installed on a rigid base with a $12^{\circ}$ inclination, corresponding to the latitude of the city of Huancayo. The DC/AC conversion is performed by a three-phase SMA-SUNNY TRIPOWER 5000TL inverter with the maximum power point (MPP) function enabled. Irradiance is measured by the SMP3-A class 2 pyranometer from the manufacturer KIPP-ZONEN. The temperature is recorded by the AGS54+ sensor from the manufacturer Thermokon. Electrical measurements (voltage, current, and power) and environmental measurements (temperature and irradiance) are recorded in a data-logger every 5 minutes during the day.

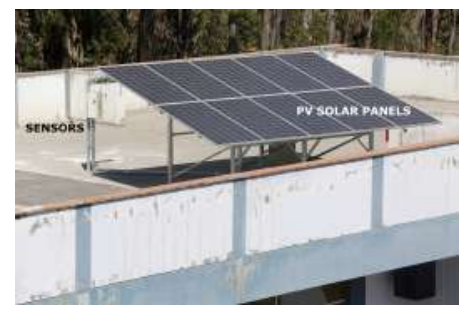

Figure 1. Experimental PV system

Table 1. Datasheet MAXPOWER CS6U-325

\begin{tabular}{lcr}
\hline Parameter & Description & Value \\
\hline $\mathrm{P}_{\max }$ & Nominal Max. Power - STC & $325 \mathrm{~W}$ \\
$\mathrm{~V}_{\mathrm{mp}}$ & Optimal Operating Voltage - STC & $37 \mathrm{~V}$ \\
$\mathrm{I}_{\mathrm{mp}}$ & Optimal Operating Current - STC & $8.78 \mathrm{~A}$ \\
$\mathrm{~V}_{\mathrm{oc}}$ & Open Circuit Voltage - STC & $45.5 \mathrm{~V}$ \\
$\mathrm{I}_{\mathrm{sc}}$ & Short Circuit Current - STC & $9.34 \mathrm{~A}$ \\
$\mathrm{k}_{\mathrm{V}}$ & Temperature Coefficient - Voc & $-0.31 \% /{ }^{\circ} \mathrm{C}$ \\
$\mathrm{k}_{\mathrm{i}}$ & Temperature Coefficient - Isc & $0.05 \% /{ }^{\circ} \mathrm{C}$ \\
$\mathrm{N}_{\mathrm{s}}$ & Cell Arrangement & $72(6 \times 12)$ \\
$\mathrm{T}_{\mathrm{NMOT}}$ & Nominal Module Operating Temperature - $\mathrm{NMOT}^{\mathrm{b}}$ & $43{ }^{\circ} \mathrm{C}$ \\
$\mathrm{T}_{\mathrm{a}}$ & Ambient Temperature - NMOT & $20{ }^{\circ} \mathrm{C}$ \\
\hline
\end{tabular}

${ }^{a}$ STC: Standard Test Conditions.

${ }^{\mathrm{b}}$ NMOT: Nominal Module Operating Temperature 


\subsection{Single diode model - photovoltaic panel}

The PV system can be modeled through the single-diode model [22]. Figure 2 shows the electrical circuit that defines this model. The characteristic equation I-V of the PV system from the electrical circuit is represented in (1):

$$
I=I_{L}-I_{o}\left[\exp \left(\frac{V+I R_{s}}{n_{i} N_{s} V_{t}}\right)-1\right]-\frac{V+I R_{s}}{R_{s h}}
$$

where $I$ and $V$ represent the current and voltage of the PV module respectively, $I_{L}$ represents the photoelectric current, $I_{o}$ the inverse saturation current of the diode, the ideal factor of the diode represented by $n_{i}$, whereas $N_{s}$ represents the cells connected in series, and $V_{t}$ the thermal voltage. The resistors $R_{s}$ and $R_{s h}$ represent the series and shunt losses respectively [19]. The transcendental equation expressed in (1) is solved through numerical methods. The methodology of Gauss-Seidel is used in [18]; however the method of Newton-Rapshon is most commonly used in the scientific literature $[5,7,17]$. There are more sophisticated PV models than the SDM [4]; however, the SDM is the most studied model and presents accurate results when evaluated under variable temperature and irradiance conditions [5-8, 13, 14, 17-20, 23, 24].

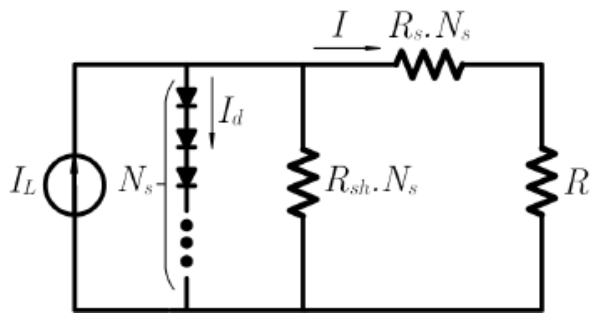

Figure 2. Single diode model - PV system

\subsection{PV system parameter estimation: Known methods}

This section refers to the known methods to estimate the five parameters of the SDM; the estimation procedure is done in STC and not STC.

\subsubsection{Parameter estimation under STC}

The methodologies propose an iterative and analytical process to calculate the unknown parameters. Basically, the methods are used to estimate the I-V and P-V curves of the PV system. The method proposed in [5] simplifies the SDM considering $I_{L}=I_{s c}$. The $I_{o}$ is obtained through (2) and the $R_{s}, R_{s h}$, and $n_{i}$ parameters are obtained by simultaneously solving (3), (4), and (5).

$$
\begin{gathered}
I_{o}=\frac{I_{L}-V_{o c} / R_{s h}}{\exp \left[V_{o c} /\left(n_{i} N_{s} V_{t}\right)-1\right]} \\
I_{m p}=\lambda_{1}-\left(I_{s c}-\frac{V_{o c}-I_{s c} R_{s}}{R_{s h}}\right) \lambda_{2} \\
-\frac{1}{R_{s h}}=\frac{-\frac{1}{R_{s h}}-\lambda_{3} \lambda_{4}}{1+R_{s} \lambda_{3} \lambda_{4}+\frac{R_{s}}{R_{s h}}} \\
I_{m p}+V_{m p} \frac{-\lambda_{2} \lambda_{3}-\frac{1}{R_{s h}}}{1+R_{s} \lambda_{2} \lambda_{3}+\frac{R_{s}}{R_{s h}}}=0
\end{gathered}
$$

where the factors $\lambda_{1}=I_{s c}-\left(V_{m p}+I_{m p} R_{s}-I_{s c} R_{s}\right) / R_{s h}, \lambda_{2}=\exp \left[\left(V_{m p}+I_{m p} R_{s}-V_{o c}\right) /\left(n_{i} N_{s} V_{t}\right)\right]$, $\lambda_{3}=\left(I_{s c} R_{s h}-V_{o c}+I_{s c} R_{s}\right) /\left(n_{i} N_{s} V_{t} R_{s h}\right)$, and $\lambda_{4}=\exp \left[\left(I_{s c} R_{s}-V_{o c}\right) /\left(n_{i} N_{s} V_{t}\right)\right]$.

The approach proposed in [7] considers the four-parameter SDM, neglecting the value of $R_{s h}$, considering $I_{L}=I_{s c}$. The $I_{o}$ is obtained through (6). The $n_{i}$ factor depends on the PV module technology and is 
constant. The estimation of $R_{s h}$ and $R_{s}$ is done in the MPP of the I-V curve. The estimation of $R_{s h}$ is done according to (7) through a gradual increase of $R_{s}$.

$$
\begin{gathered}
I_{o}=\frac{I_{L}}{\exp \left[V_{o c} /\left(n_{i} N_{s} V_{t}\right)-1\right]} \\
R_{s h}=\frac{V_{m p}\left(V_{m p}+I_{m p} R_{s}\right)}{\lambda_{5}}
\end{gathered}
$$

where $\lambda_{5}=V_{m p} I_{L}-V_{m p} I_{o} \exp \left[\left(V_{m p}+I_{m p} R_{s}\right) /\left(n_{i} N_{s} V_{t}\right)\right]+V_{m p} I_{o}-P_{\max , e}$.

The method proposed in [8] provides an iterative solution to find the values of $R_{s}, R_{s h}$ e $I_{L}$ considering constant the value of $n_{i}$ that depends on the type of technology of the PV module. The $I_{o}$ value is approximated by (6), the iterative process ends when the lowest value is obtained for the (8), (9) y (10) expressions.

$$
\begin{gathered}
E r r_{1}=\frac{V_{m p}}{I_{m p}}-R_{s}-\frac{n_{i} N_{s} V_{t} R_{s h}}{I_{o} R_{s h} \lambda_{2}+n_{i} N_{s} V_{t}} \\
\operatorname{Err}_{2}=\frac{V_{m p}+I_{m p} R_{s}}{I_{L}-I_{m p}-I_{o}\left(\lambda_{2}-1\right)}-R_{s h} \\
\operatorname{Err}_{3}=\frac{R_{s}+R_{p}}{R_{p}} I_{s c}-I_{L}
\end{gathered}
$$

\subsubsection{Parameter estimation in non-STC}

The parameters of the SDM depend on the environmental conditions of temperature and irradiance. The conversion of STC to other conditions different from temperature and irradiance is necessary for each parameter [19]. The dependence of temperature and irradiance on the parameters of the SDM is based on the principle of overlapping [25]. In [4, 5, 7] the PV cell temperature is assumed to be the ambient temperature. In [8] the PV cell temperature is approximated from the ambient temperature, which allows for a better characterization for the PV panel model. Table 2 shows the comparison of different criteria for the dependence of the SDM parameters on temperature and irradiance.

Table 2. Dependence of the SDM parameters: Temperature (T) and Irradiance (I)

\begin{tabular}{lccccc}
\hline Reference & \multicolumn{5}{c}{ Parameter } \\
& $\mathrm{R}_{\mathrm{S}}$ & $\mathrm{R}_{\mathrm{sh}}$ & $\mathrm{n}_{\mathrm{i}}$ & $\mathrm{I}_{\mathrm{O}}$ & $\mathrm{I}_{\mathrm{L}}$ \\
\hline$[4]$ & $\mathrm{T}$ & - & $\mathrm{T}$ & $\mathrm{T}-\mathrm{I}$ & $\mathrm{T}-\mathrm{I}$ \\
{$[5]$} & - & - & - & T-I & T-I \\
{$[6]$} & $\mathrm{T}-\mathrm{I}$ & - & - & T-I & T-I \\
{$[7]$} & - & - & - & $\mathrm{T}$ & T-I \\
{$[8]$} & - & - & - & $\mathrm{T}$ & T-I \\
{$[13]$} & - & - & - & T-I & T-I \\
{$[14]$} & - & - & $\mathrm{T}$ & $\mathrm{T}$ & T-I \\
{$[19]$} & T-I & $\mathrm{I}$ & $\mathrm{T}$ & $\mathrm{T}$ & T-I \\
\hline
\end{tabular}

\subsection{PV system parameter estimation: proposed methodology}

The scientific literature in [26] shows the classification of irradiance $\left(\mathrm{W} / \mathrm{m}^{2}\right)$ in two levels: the values below 250 are regarded as lows levels whereas highs levels include values above 500. In this investigation, the classification of irradiance according to [26] is made by adding the average level of irradiance for values between 200 and 500. The SDM with low irradiance levels has little accuracy in modeling poly-crystalline silicone panels [27]. In this research, a methodology is implemented to evaluate the four-parameter SDM at the medium (200-500) and high (500) irradiance levels, considering the approximation of the module temperature from the ambient temperature. The proposed methodology considers the experimental measurements (irradiance, DC current, ambient temperature, and DC voltage) to solve equation (1) and estimate the $R_{s}$ and $n_{i}$ values. The four-parameter SDM makes an exact approximation of both parameters [26]. The four-step methodology is presented below: 
- Step I - Calculation of the temperature factor $K_{T}$ : To obtain an accurate model and approximate the real behavior of the PV system, the ambient temperature $\left(T_{m}\right)$ is used to estimate the cell temperature $\left(T_{\text {cell }}\right)$ according to [8]. The $K_{T}$ is calculated through (11) using the module operation temperature $\left(T_{N M O T}\right)$, the ambient temperature $\left(T_{a}\right)$, and the irradiance level $\left(\operatorname{Irr}_{a}\right)$; these three parameters under NMOT conditions. Finally the irradiance measurement $(G)$ is corrected with $K_{T}$ and $T_{m}$ according to (12).

- Step II - Calculation of the current $I_{o}$ :

The accuracy of the SDM is improved through (13) to cancel the error of the model in the vicinity of $V_{o c}$ and simplify the model [7]. The $I_{o}$ current is estimated according to (13), using the temperature coefficients $K_{i}$ and $K_{v}$.

- Step III - Calculation of the photo-current $I_{L}$ :

The superposition principle is used to establish the dependence of irradiance and temperature for the $I_{L}$ [25]. This current is estimated with (14), considering the nominal irradiance $\left(G_{S T C}\right), I s c, T_{S T C}$ based on the datasheet, the values previously calculated, $T_{\text {cell }}, K_{T}$, and the measurement of irradiance $G$.

- Step IV - Calculation of series resistance $R_{s}$ and $n_{i}$ :

The $R_{s}$ value obtained from (1) is shown in (15), neglecting the value of $R_{s h}$. In the event that $I_{L}-I$ is negative, the $R_{s}$ presents imaginary values due to the logarithmic factor. This situation occurs at low irradiance and temperature levels. The formulation in (15) presents two unknowns: $R_{s}$ and $n_{i}$, to estimate both variables. This equation is solved in an iterative way to calculate the best value of $R_{s}$ with an increase of $n_{i}$ from 0 to 5 . The justification for the extreme value of 5 corresponds to the a-Si-H Triple type panel technology [17]. The best value of $R_{s}$ corresponds to the lowest value available for $n_{i}$. This iterative procedure is repeated for each of the measurements recorded during the day.

$$
\begin{gathered}
K_{T}=\left(T_{\text {NMOT }}-T_{a}\right) / \text { Irr }_{a} \\
T_{\text {cell }}=G K_{T}+T_{m} \\
I_{o}=\frac{I_{s c}+K_{i}\left(T_{\text {cell }}-T_{S T C}\right)}{\exp \left[\frac{V_{o c}+K_{v}\left(T_{\text {cell }}-T_{S T C}\right)}{n_{i} N_{s} V_{t}}\right]-1} \\
I_{L}=\left(G / G_{S T C}\right)\left[I_{S C}+K_{T}\left(T_{c e l l}-T_{S T C}\right)\right] \\
R_{s}=\left\{\left(\log \left[\left(I_{L}-I\right) / I_{o}+1\right]\left(n_{i} N_{s} V_{t}\right)-V\right\} / I\right.
\end{gathered}
$$

\section{RESULTS AND DISCUSSION}

In this research, through Matlab/Simulink programming, the methodologies exposed in $[5,7,8]$ have been used to calculate the parameters of the SDM and to determine the parameters for different values of temperature and irradiance during the day (8:00 - 16:00 hours). The PV power estimation capacity of the SDM using the known methodologies and the proposed methodology is validated through the experimental power measurements of the $3 \mathrm{kWp}$ experimental installation. The accuracy of the different methodologies including the proposed methodology is analyzed through two statistical indicators: The root-mean-square error (RMSE) and the relative root-mean-square error (RRMSE). These indicators express the model's accuracy [28, 29].

\subsection{Estimation of the parameters of the MAXPOWER CS6U-325 module in STC}

The technical characteristics shown in Table 1 are used to estimate the five unknown parameters of the SDM according to section 2.3, where the methodologies exposed in $[5,7,8]$ are used. The estimated parameters of the SDM are shown in Table 3. About $R_{s}$ and $R_{s h}$, the values obtained are not convergent, because each methodology has a combination of analytical and iterative aspects to determine the parameters of the SDM. For the results of $R_{s}$ with the [5] and [7] methods, a difference of $59 \mathrm{~m} \Omega$ was determined and between the [5] and [7] methods a difference of $42 \mathrm{~m} \Omega$. Regarding the value of $R_{s h}$, the results show a sizeable difference between the three methods used. The value of $n_{i}$ shows a similarity when using the methods exposed in [7] and [8]. However, when using the method exposed in [5], it results in a difference of $9 \%$ in comparison to the other methodologies. Because all three methods use $I_{L}=I_{s c}$, the result of $I_{o}$ is negligible. 
Table 3. PV System Parameters Estimation - STC

\begin{tabular}{lccr}
\hline Parameter & \multicolumn{3}{c}{ Method } \\
& {$[5]$} & {$[7]$} & {$[8]$} \\
\hline $\mathrm{R}_{\mathrm{s}}(\mathrm{m} \Omega)$ & 256.360 & 197 & 214 \\
$\mathrm{R}_{\mathrm{sh}}(\mathrm{k} \Omega)$ & 4.752 & 36.933 & 0.980 \\
$\mathrm{n}_{\mathrm{i}}$ & 1.180 & 1.300 & 1.300 \\
$\mathrm{I}_{\mathrm{o}}(\mathrm{nA})$ & 8.247 & 56.650 & 56.136 \\
$\mathrm{I}_{\mathrm{L}}(\mathrm{A})$ & 9.340 & 9.340 & 9.340 \\
\hline
\end{tabular}

\subsection{Classification of irradiance and temperature measurements}

The following research used eight-day irradiance and temperature measurements for 2019 and 2020. The measurements were taken from 8:00 - 16:00 hours (the time of highest irradiance) with a record taken down every 5 minutes. In total, 97 measurements were used for each day. Table 4 shows the calculation of standard deviation $(\sigma)$, mean $(\bar{x})$, and coefficient of variation $(\sigma / \bar{x})$. For the eight cases analyzed, the $\bar{x}$ is representative because all values for the coefficient of variation are lower than $80 \%$. With the $\bar{x}$ index, the classification of medium and high irradiance according to Section 2.4 is made.

Table 4. Clasification of Experimental Measurements: Irradiance and Temperature

\begin{tabular}{lcccccc}
\hline Case & \multicolumn{3}{c}{ Irradiance $\left(\mathrm{W} / \mathrm{m}^{2}\right)$} & \multicolumn{3}{c}{ Temperature (K) } \\
& $\sigma$ & $\bar{x}$ & $\sigma / \bar{x}$ & $\sigma$ & $\bar{x}$ & $\sigma / \bar{x}$ \\
\hline Medium Irradiance & & & & & & \\
$2020 / 03 / 30$ & 140.6689 & 297.9555 & 0.4721 & 2.5124 & 285.3475 & 0.0088 \\
$2020 / 04 / 29$ & 202.7555 & 444.7498 & 0.4559 & 3.0318 & 293.2009 & 0.0103 \\
$2020 / 01 / 20$ & 169.8526 & 444.7233 & 0.3819 & 2.8156 & 292.5276 & 0.0096 \\
2019/11/30 & 216.2121 & 481.5473 & 0.4490 & 2.4849 & 294.1576 & 0.0084 \\
High Irradiance & & & & & & \\
2020/01/06 & 156.3721 & 569.0823 & 0.2748 & 3.6622 & 294.1918 & 0.0124 \\
2020/02/21 & 202.5199 & 562.3305 & 0.3601 & 4.0584 & 294.5444 & 0.0138 \\
2019/08/10 & 181.3876 & 766.6862 & 0.2366 & 2.9421 & 294.2186 & 0.0100 \\
$2020 / 05 / 13$ & 230.0101 & 735.7995 & 0.3126 & 4.1659 & 294.1500 & 0.0142 \\
\hline
\end{tabular}

\subsection{Estimation of the parameters of the MAXPOWER CS6U-325 module in non-STC}

Each of the methodologies in $[5,7,8]$ has a different criterion for correcting and estimating the parameters of the SDM under conditions other than STC. As described in Section 2.3 and Table 2, the correction of the results of Table 3 was made. The SDM parameters allowed for solving the transcendental equation of the PV through Newton Raphson's Method and obtaining the value of $I$ in the 8:00 to 16:00 hours. Consequently, with the DC voltage measured the PV power was also obtained for the SDM.

\subsection{MAXPOWER CS6U-325 module parameter estimation: Proposed methodology}

The methodology proposed in Section 2.4 is used to calculate the four unknown parameters of the SDM using the analytical and iterative approach. The value of $R_{s h}$ is neglected.

\subsubsection{Series resistance calculation - variable condition}

Using the experimental measurements of irradiance and temperature, the final calculation of $R_{s}$ is made, considering only the positive values. The results of Figure 3 show that, for medium irradiance, the $R_{s}$ is variable from $1 \mathrm{~m} \Omega$ to values close to $6 \mathrm{~m} \Omega$. Figure 4 corresponds to high values of irradiance, the behavior of $R_{s}$ is practically constant with values lower than $3 m \Omega$. The results with null values in Figures 3 and 4 correspond to regions where the value of $R_{s}$ is imaginary. This phenomenon occurs when $I_{L}-I$ is negative. In these short periods of time, there are low levels of irradiance and temperature due to a partially cloudy sky. The $R_{s}$ is not constant because it is a function of the behavior of $n_{i}$, which, in turn, is a function of temperature and irradiance according to equations (11), (12), (13), (14), and (15). The values obtained for medium irradiances are different from the results of the methods proposed in $[5,7,8]$; however, for high irradiances, this parameter can be considered constant. 


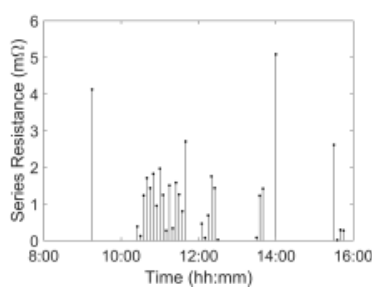

(a)

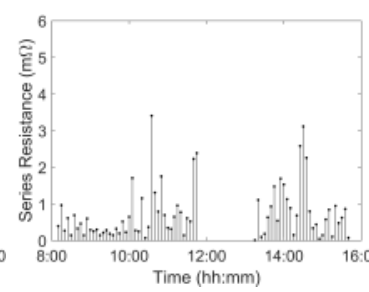

(b)

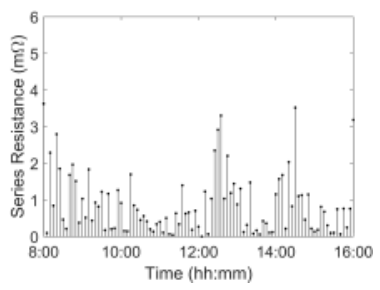

(c)

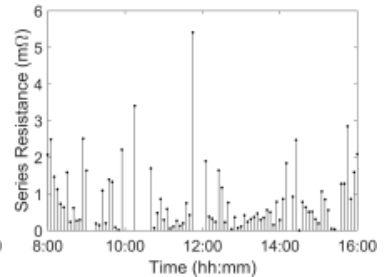

(d)

Figure 3. Results of series resistance calculation - medium Irradiance,

(a) 2020-03-30, (b) 2020-04-29, (c) 2020-01-20 and (d) 2019-11-30

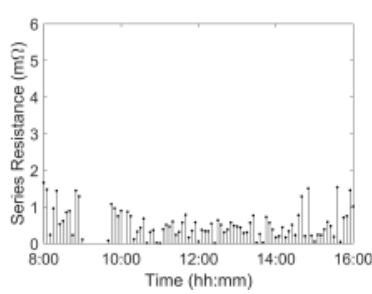

(a)

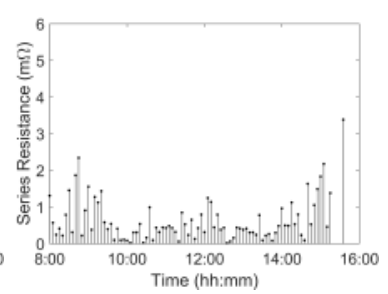

(b)

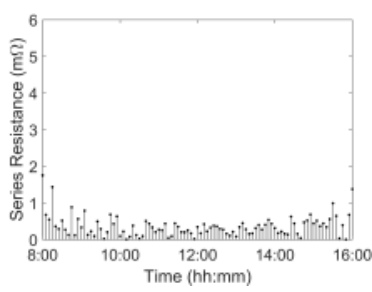

(c)

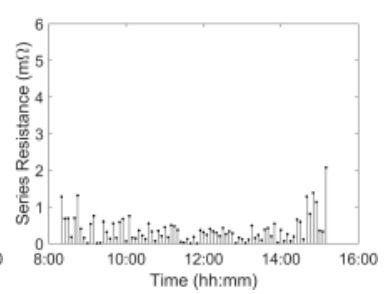

(d)

Figure 4. Results of series resistance calculation - high irradiance,

(a) 2020-01-06, (b) 2020-02-21, c) 2019-08-10 and (d) 2020-05-13

Table 5. Statistical indicators: Variable and fixed series resistance for PV power assessment

\begin{tabular}{lccclll}
\hline Case & \multicolumn{3}{c}{ Variable $\mathrm{R}_{\mathrm{s}}$} & & \multicolumn{3}{c}{ Fixed R } \\
& $\operatorname{RMSE}(W)$ & $\operatorname{RRMSE}(\%)$ & $\mathrm{R}$ & $\operatorname{RMSE}(W)$ & $\operatorname{RRMSE}(\%)$ & $\mathrm{R}$ \\
\hline $\begin{array}{l}\text { Medium Irradiance } \\
2020 / 01 / 20\end{array}$ & $2.6 \mathrm{e}-14$ & $2.0 \mathrm{e}-14$ & 1 & 0.2317 & 0.1749 & 0.9999 \\
$\begin{array}{l}\text { High Irradiance } \\
\text { 2019/08/10 }\end{array}$ & & & & & & \\
\hline
\end{tabular}

Table 6. Statistical indicators: PV power assessment

\begin{tabular}{lcccccccc}
\hline Data & \multicolumn{4}{c}{ RMSE $(W)$} & \multicolumn{5}{c}{ RRMSE (\%) } \\
& {$[5]$} & {$[7]$} & {$[8]$} & {$[\mathrm{PM}]^{\mathrm{a}}$} & {$[5]$} & {$[7]$} & {$[8]$} & {$[\mathrm{PM}]$} \\
\hline Medium Irradiance & & & & & & & & \\
2020/03/30 & 12.3075 & 13.8956 & 11.9573 & 2.7368 & 7.1675 & 8.0924 & 6.9635 & 2.6758 \\
2020/04/29 & 11.0267 & 13.3221 & 12.6768 & 4.2320 & 6.5282 & 7.8872 & 7.5051 & 3.0277 \\
2020/01/20 & 9.83510 & 4.4872 & 12.1362 & 0.2317 & 9.6160 & 4.3873 & 11.8659 & 0.1749 \\
2019/11/30 & 12.2952 & 13.0749 & 11.0958 & 1.7152 & 8.7962 & 9.3540 & 7.9381 & 1.2034 \\
& & & & & & & & \\
High Irradiance & & & & & & & & \\
2020/01/06 & 12.4220 & 15.0071 & 7.5600 & 3.8402 & 9.3764 & 11.3277 & 5.7064 & 2.2364 \\
2020/02/21 & 20.1444 & 21.4444 & 16.0448 & 0.7861 & 14.1336 & 15.0457 & 11.2572 & 0.4654 \\
2019/08/10 & 9.9995 & 12.6058 & 14.1610 & 0.3919 & 4.3698 & 5.5088 & 6.1884 & 0.1713 \\
2020/05/13 & 17.3125 & 16.8730 & 20.6361 & 14.8959 & 7.5927 & 7.3999 & 9.0503 & 6.5328 \\
\hline
\end{tabular}

${ }^{\mathrm{a}}[\mathrm{PM}]$ : Proposed Methodology.

\subsubsection{Series resistance calculation - fixed condition}

This case considers a constant $R_{s}$ in order to reduce the complexity of the SDM. The authors in [5, $7,8]$ represent diverse criteria to correct series resistance in different conditions of temperature and irradiance, 
in the present methodology a constant value of this parameter is considered for conditions different from STC. The value of $R_{s}$ has been considered constant. The chosen value corresponds to the maximum value of the eight cases evaluated $(6 \mathrm{~m} \Omega)$ as shown in Figures 3 and 4. Table 5 shows the error incurred in making this approach, is negligible with the values shown for RMSE and RRMSE. The results obtained allow us to conclude that considering $R_{s}$ constant has two main advantages: The first advantage corresponds to the small error committed in the SDM as shown in Table 5. The second advantage corresponds to the elimination of null values in the calculation of $R_{s}$. When considering constant this variable, all the calculations of $n_{i}$ are also valid. Table 6 shows a comparison between the methodologies described in $[5,7,8]$ and the proposed methodology. The statistical results show that the proposed methodology has less error than the other conventional methodologies. The RRMSE indicator shows values less than $6.5 \%$ in all cases, which corresponds to an excellent classification $[30,31]$. Figures $5 a, 5 b, 5 c, 5 d, 6 a, 6 b, 6 c$, and $6 d$ show the power estimation during 8:00 to 16:00 hours for each case. These values correspond to the power of a single PV panel. The results show that, for daytime conditions when the irradiance varies slowly and quickly, the proposed method conveniently estimates the value of the photovoltaic power, in the time intervals when there is a low irradiance (Figure 5a, 5b, 5d, 6a, 6b, and 6d). A slight difference is shown concerning the measurements. This is due to the own accuracy of the unitary diode [27]. Additionally, it is determined that the SDM as presented in this research, depends basically on the value of $n_{i}$. This parameter is not constant and depends on the behavior of irradiance. Figure 7a shows the cases for low irradiance in the case of partially cloudy and sunny days that are quite heterogeneous. In the time intervals when the irradiance is variable, the $n_{i}$ factor has a greater degree of dependency. Figure $7 \mathrm{~b}$ shows the case of high irradiance where the $n_{i}$ factor also varies according to the level of irradiance.

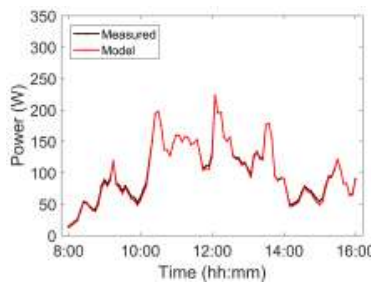

(a)

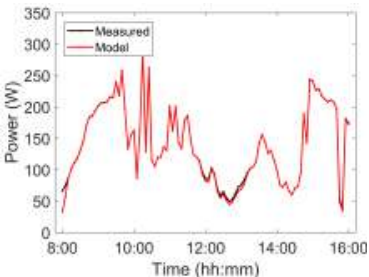

(b)

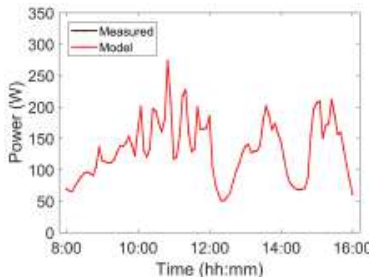

(c)

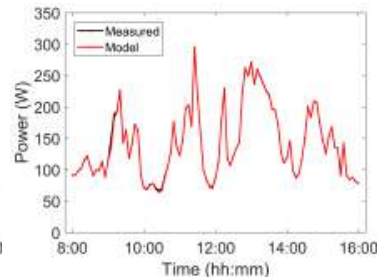

(d)

Figure 5. Test result showing the measured and model data of photovoltaic power - medium irradiance, (a) 2020-03-30, (b) 2020-04-29, (c) 2020-01-20 and (d) 2019-11-30

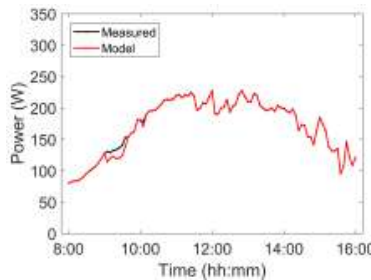

(a)

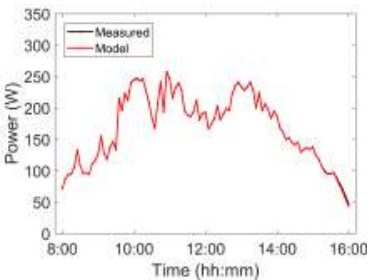

(b)

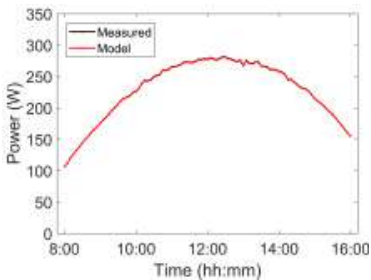

(c)

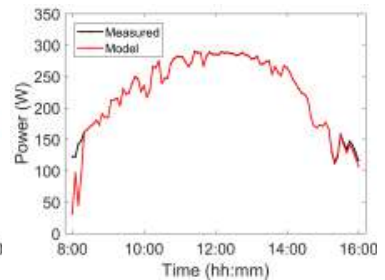

(d)

Figure 6. Test result showing the measured and model data of photovoltaic power - high irradiance, (a) 2020-01-06, (b) 2020-02-21, (c) 2019-08-10 and (d) 2020-05-13 


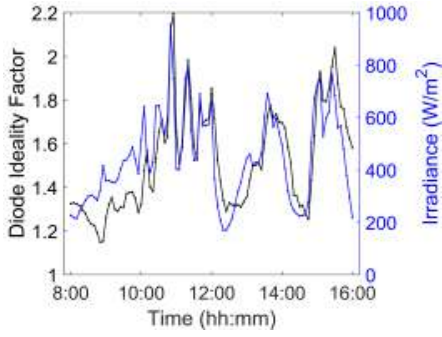

(a)

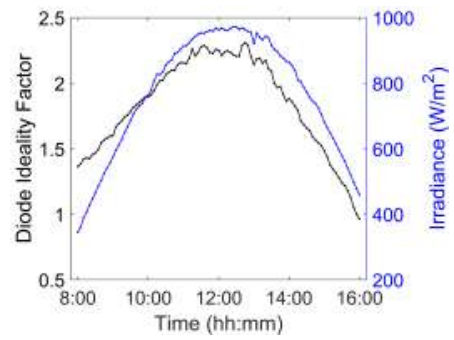

(b)

Figure 7. Test result showing the measured and model data of ideal diode factor, (a) 2020-01-20 (medium irradiance) and (b) 2019-08-10 (high irradiance)

\section{CONCLUSION}

In the present work, an analytical and iterative methodology has been proposed to determine the parameters of the unitary model of the PV panel. It has been used as a model with four parameters, where $I_{L}$ and $I_{o}$ are calculated analytically. It was determined that the parameter $R_{s}$ depends on the irradiance and temperature; however, if considered constant, the results show that the model has a negligible error. The factor $n_{i}$ shows behaviors closely related to irradiance. Accordingly, this parameter must be variable to obtain a more accurate model. Through the statistical indicators RMSE and RRMSE, it has been demonstrated that the proposed methodology is more precise than the conventional ones. This methodology can be used to accurately estimate the four unknown parameters of the single diode model and to estimate the power produced by a PV system.

\section{ACKNOWLEDGMENT}

The author thanks the National University of the Center of Peru (UNCP) and the Department of Electrical and Electronic Engineering for the technical facilities used for the development of this research.

\section{REFERENCES}

[1] IRENA, "Renewable Capacity Highlights," Tech. Rep., 2020. [Online]. Available: https://www.irena.org/publications/2020/Mar/Renewable-Capacity-Statistics-2020

[2] U. S. E. I. Administration, "Annual Energy Outlook 2020," Tech. Rep., 2020. [Online]. Available: https://www.eia.gov/outlooks/aeo/

[3] M. Suthar, G. Singh, and R. Saini, "Comparison of mathematical models of photo-voltaic (pv) module and effect of various parameters on its performance," in 2013 International Conference on Energy Efficient Technologies for Sustainability. IEEE, 2013, pp. 1354-1359.

[4] W. Xiao, W. G. Dunford, and A. Capel, "A novel modeling method for photovoltaic cells," in 2004 IEEE 35th Annual Power Electronics Specialists Conference (IEEE Cat. No. 04CH37551), vol. 3. IEEE, 2004, pp. 1950-1956.

[5] T. Esram, "Modeling and control of an alternating-current photovoltaic module," Ph.D. dissertation, University of Illinois at Urbana-Champaign, 2010.

[6] E. A. Silva, F. Bradaschia, M. C. Cavalcanti, and A. J. Nascimento, "Parameter estimation method to improve the accuracy of photovoltaic electrical model," IEEE Journal of Photovoltaics, vol. 6, no. 1, pp. 278-285, 2015.

[7] M. G. Villalva, J. R. Gazoli, and E. Ruppert Filho, "Comprehensive approach to modeling and simulation of photovoltaic arrays," IEEE Transactions on power electronics, vol. 24, no. 5, pp. 1198-1208, 2009.

[8] H. B. Vika, "Modelling of Photovoltaic Modules with Battery Energy Storage in Simulink/Matlab," Trondheim Norwegian University of Science and Technology, vol. 99, 2014.

[9] H. K. Mehta, H. Warke, K. Kukadiya, and A. K. Panchal, "Accurate expressions for single-diode-model solar cell parameterization," IEEE Journal of Photovoltaics, vol. 9, no. 3, pp. 803-810, 2019.

[10] J. Galarza and D. Condezo, "Comparative study for one-diode photovoltaic model using experimental data," in 2020 IEEE International Symposium on Sustainable Energy, Signal Processing and Cyber Security (iSSSC). IEEE, 2020, pp. 1-6.

[11] A. Şentürk, "New method for computing single diode model parameters of photovoltaic modules," Renewable energy, vol. 128, pp. 30-36, 2018.

[12] J. Galarza and D. Condezo, "Parameter correction for the photovoltaic one-diode model," in 2020 IEEE 
International Symposium on Sustainable Energy, Signal Processing and Cyber Security (iSSSC). IEEE, 2020, pp. 1-5.

[13] T. Khatib, K. Sopian, and H. A. Kazem, "Actual performance and characteristic of a grid connected photovoltaic power system in the tropics: A short term evaluation," Energy Conversion and Management, vol. 71, pp. 115-119, 2013.

[14] A. N. Celik and N. Acikgoz, "Modelling and experimental verification of the operating current of monocrystalline photovoltaic modules using four-and five-parameter models," Applied energy, vol. 84, no. 1, pp. 1-15, 2007.

[15] G. Vokas, A. Machias, and J. Souflis, "Computer modeling and parameters estimation for solar cells," in [1991 Proceedings] 6th Mediterranean Electrotechnical Conference. IEEE, 1991, pp. 206-209.

[16] H. Yamashita, K. Tamahashi, M. Michihira, A. Tsuyoshi, K. Amako, and M. Park, "A novel simulation technique of the pv generation system using real weather conditions," in Proceedings of the Power Conversion Conference-Osaka 2002 (Cat. No. 02TH8579), vol. 2. IEEE, 2002, pp. 839-844.

[17] T. Ayodele, A. Ogunjuyigbe, and E. Ekoh, "Evaluation of numerical algorithms used in extracting the parameters of a single-diode photovoltaic model," Sustainable Energy Technologies and Assessments, vol. 13 , pp. 51-59, 2016.

[18] A. Chatterjee, A. Keyhani, and D. Kapoor, "Identification of photovoltaic source models," IEEE Transactions on Energy conversion, vol. 26, no. 3, pp. 883-889, 2011.

[19] M. Farhoodnea, A. Mohamed, T. Khatib, and W. Elmenreich, "Performance evaluation and characterization of a 3-kWp grid-connected photovoltaic system based on tropical field experimental results: new results and comparative study," Renewable and Sustainable Energy Reviews, vol. 42, pp. 1047-1054, 2015.

[20] U. Jadli, P. Thakur, and R. D. Shukla, "A new parameter estimation method of solar photovoltaic," IEEE Journal of Photovoltaics, vol. 8, no. 1, pp. 239-247, 2017.

[21] C. Solar, "Canadian Solar-MaxPower CS6U-325 Datasheet v5.571," Tech. Rep., 2018. [Online]. Available: https://www.canadiansolar.com/

[22] S. Liu and R. A. Dougal, "Dynamic multiphysics model for solar array," IEEE Transactions on Energy Conversion, vol. 17, no. 2, pp. 285-294, 2002.

[23] M. L. Azad, P. K. Sadhu, S. Das, B. Satpati, A. Gupta, P. Arvind, and R. Biswas, "An improved approach to design a photovoltaic panel," Indonesian Journal of Electrical Engineering and Computer Science, vol. 5, no. 3, pp. 515-520, 2017.

[24] S. Shongwe and M. Hanif, "Comparative analysis of different single-diode pv modeling methods," IEEE Journal of photovoltaics, vol. 5, no. 3, pp. 938-946, 2015.

[25] D. Sera, R. Teodorescu, and P. Rodriguez, "Pv panel model based on datasheet values," in 2007 IEEE international symposium on industrial electronics. IEEE, 2007, pp. 2392-2396.

[26] C. Whitaker, T. Townsend, H. Wenger, A. Iliceto, G. Chimento, and F. Paletta, "Effects of irradiance and other factors on pv temperature coefficients," in The Conference Record of the Twenty-Second IEEE Photovoltaic Specialists Conference-1991. IEEE, 1991, pp. 608-613.

[27] G. Petrone, C. A. Ramos-Paja, and G. Spagnuolo, Photovoltaic sources modeling. Wiley Online Library.

[28] K. Mohammadi, O. Alavi, A. Mostafaeipour, N. Goudarzi, and M. Jalilvand, "Assessing different parameters estimation methods of weibull distribution to compute wind power density," Energy Conversion and Management, vol. 108, pp. 322-335, 2016.

[29] J. Galarza, D. Condezo, B. Camayo, E. Mucha et al., "Assessment of wind power density based on weibull distribution in region of junin, peru," Energy and Power Engineering, vol. 12, no. 01, p. 16, 2019.

[30] M.-F. Li, X.-P. Tang, W. Wu, and H.-B. Liu, "General models for estimating daily global solar radiation for different solar radiation zones in mainland china," Energy conversion and management, vol. 70, pp. $139-148,2013$.

[31] P. Jamieson, J. Porter, and D. Wilson, "A test of the computer simulation model arcwheat1 on wheat crops grown in new zealand," Field crops research, vol. 27, no. 4, pp. 337-350, 1991.

\section{BIOGRAPHY OF AUTHOR}

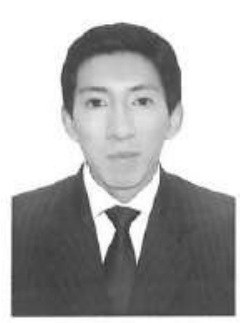

Jose Galarza received the MSc. degree in Electrical Engineering from the Polytechnic University of Madrid. He is affiliated to the Department of Electrical Engineering - National University of the Center of Peru. His research interests include renewable energy technologies, HVDC electric power transmission system and power electronic converters for motion control.

Further info on his homepage: https://orcid.org/0000-0001-5569-6541 